Bangladesh J. Bot. 42(1): 155-159, 2013 (June)

\title{
IDENTIFICATION OF TRUE HYBRID PROGENIES IN CASSAVA USING SIMPLE SEQUENCE REPEAT (SSR) MARKERS
}

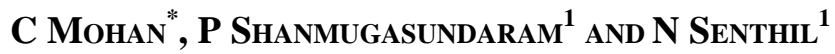 \\ Central Tuber Crops Research Institute, Sreekariyam, Thiruvananthapuram, \\ Kerala-695 017, India \\ Key words: Cassava, Genotyping, True hybrid, SSR markers
}

\begin{abstract}
For the maping of Cassava mosaic disease (CMD) resistance gene, $\mathrm{CO} 2$ and MNga-1 parents were used for hybridization to develop $F_{1}$ hybrid seeds and 153 progenies were planted in the field for genotyping. Out of the 75 SSR primers used for parental polymorphism, 57 produced polymorphic bands between parents and these were used to screen the 153 progenies of the cross for genotyping. Out of these 57 SSR primer pairs SSRY32, SSRY36, SSRY83, SSRY339, NS149 and NS890 loci produced single marker which clearly distinguished the parents. Based on the said six primers, 12 progenies out of 153 were identified as self pollinated seeds of $\mathrm{CO} 2$ female parent. So these types of SSR markers were very much useful for identification of true hybrid seedlings in the early stage of growth and genotyping of the progenies more accurately for gene mapping.
\end{abstract}

\section{Introduction}

Cassava, (Manihot esculenta Crantz) belonging to Euphorbiaceae, is one of the most important staple food crops in tropics and grown widely under diverse environmental conditions. The tuberous root crop has its origin in South America. Because of the out-crossing nature of the crop (Alves 2002), it is very important to get the hybrid seeds under controlled conditions for developing mapping population and genotype with DNA markers. Identification of male and female parent specific markers will allow differentiation of true hybrids from selfed parental and outcrossed lines in $\mathrm{F}_{1}$ because it contains DNA from both the parents. Molecular markers, such as RAPD, ISSR, SSR, AFLP and RFLP have been used in cultivar fingerprinting, seed purity testing and germplasm identification for many crops (Crockett et al. 2000, Dongre and Parkhi 2005, Liu et al. 2004, Nandakumar et al. 2004). Among the various molecular markers currently available, simple sequence repeats (SSR), also known as microsatellites, are widely accepted as reliable. SSRs have proven to be abundant and well distributed throughout the genome of plants. Because they are co-dominant, detect high levels of allelic diversity, and are assayed efficiently by the PCR (Moyib et al. 2007, Manigbas and Villagas 2004, Ye-yun et al. 2005).

In melon, the hybrid purity of $F_{1} S$ was identified using SSR markers and contamination of $F_{1}$ hybrid seeds caused by self-inbred and other unknown pollens can be effectively and more reliably detected with SSR primers (Ju-Fen et al. 2008). In maize, the most widely used method for determination off-sib levels in the $F_{1}$ hybrid is the grow out test (GOT) that involves growing a representative sample of the seed followed by analysis of several morphological and floral characteristics of the plant to determine the sib levels. This method is time-consuming and costly, and requires extensive use of land. Wu et al. (2010) clearly demonstrated that SSR marker should be useful for assessing purity of maize hybrid, even if the hybrid is derived from two related parental lines. Similarly genetic purity of hybrids was identified by SSR, ISSR, RAPD and other

*Author for correspondence: <cmsan99@gmail.com>. ${ }^{1}$ Tamil Nadu Agricultural University, Coimbatore, Tamil Nadu - 641 003, India. 
markers in rice (Yashitola et al. 2002, Hashemi et al. 2009), cotton (Wu et al. 2001, Asif et al. 2009, Dongre et al. 2011), peanut (Gomez et al. 2008), sugarcane (Zhang et al. 2009), sunflower (Iqbal et al. 2010) and cabbage (Liu et al. 2007). Bianco et al. (2011) used ISSR markers for identification of $F_{1}$ hybrids in artichoke and suggested that morphological trait alone is not sufficient to evaluate the offspring precisely. These markers allow the early identification of true hybrids for further evaluation and simultaneously, enable the early disposal of non-hybrids, thus delivering substantial savings in time and resources for true population development. The present studies investigated, usefulness of SSR/microsatellite marker to identify true hybrid progenies in cassava for accurate molecular marker genotyping and gene mapping.

\section{Materials and Methods}

Two cassava varieties viz. MNga-1, a CMD resistant variety and CO2, a CMD susceptible variety, were selected based on field trials conducted at Central Tuber Crop Research Institute (CTCRI), Thiruvananthapuram, Kerala and Tamil Nadu Agricultural University (TNAU), Coimbatore, Tamil Nadu to develop the mapping population. The $\mathrm{CO} 2$, a variety released from TNAU, Coimbatore, is highly susceptible to CMD, but possesses short plant type, middle branching, profuse flowering and good quality tuber with high starch content. The variety, MNga-1 (TMS30001) was developed at the IITA, Nigeria. It is a backcross derivative of cultivated cassava and wild M. glaziovii. It is a high yielding variety (29 tha) with tall plant type, top branching and good flowering.

Hybridization between $\mathrm{CO} 2$ and MNga-1 was carried out at Orchard, TNAU. Pollens from MNga-1 were collected and placed on the forcefully opened female flowers of $\mathrm{CO} 2$ between 9 and12.00 h. Pollinated female flowers were covered with cloth bags to avoid cross/self pollination through insects. Crossed seeds were collected two months after pollination. A total of 300 seeds obtained from CO2/MNga-1 cross were sown in greenhouse at TNAU for germination and seedlings of 60 days old were transplanted with a spacing of $1 \mathrm{~m}$ between plants and rows in a farmer's field at Coimbatore. The recommended crop production practices were adopted during the crop period.

Genomic DNA of the parents and $153 \mathrm{~F}_{1} \mathrm{~s}$ were isolated from young fresh leaves adopting the procedure developed by Dellaporta et al. (1983). The DNA of individual sample was quantified by using a fluorometer (DyNA Quant TM200, M/s Hoefer Pharmacia, Biotech Inc., USA) and its quality was checked on 0.8 per cent agarose gel. The final DNA concentration of all the samples was adjusted to $25 \mathrm{ng} / \mu \mathrm{l}$. A total of $75 \mathrm{SSR}$ primer pairs representing loci covering all 18 linkage groups as established by Mba et al. (2001) were synthesized from M/s Sigma Aldrich Inc. The primer pairs were used to identify polymorphic markers between $\mathrm{CO} 2$ and MNga-1. The SSR primer pairs producing polymorphic markers were surveyed on the seedlings of the $153 \mathrm{~F}_{1}$ progenies to establish their segregation patterns because of the heterozygous nature of parents. PCR conditions were maintained as described by Mba et al. (2001). The PCR was conducted in volumes of $20 \mu \mathrm{l}$ containing $25 \mathrm{ng}$ genomic DNA, $0.2 \mu \mathrm{M}$ each of forward and reverse primers, $50 \mu \mathrm{M}$ dNTPs, $1 \mathrm{X}$ buffer $\left(10 \mathrm{mM}\right.$ Tris- $\left.\mathrm{HCl}(\mathrm{pH} 8.3), 50 \mathrm{mM} \mathrm{KCl}, 1.5 \mathrm{mM} \mathrm{MgCl}_{2}\right)$ and 0.3 unit of Taq DNA polymerase (M/s Bangalore Genei Pvt. Ltd, Bangalore).

The PCR amplifications were performed on a PTC100 (M/s MJ Research Inc.) Thermal Cycler with a PCR profile of $94^{\circ} \mathrm{C}$ for 5 min followed by 30 cycles of 1 min at $94^{\circ} \mathrm{C}, 2 \mathrm{~min}$ at $58^{\circ} \mathrm{C}$, and $2 \mathrm{~min}$ at $72^{\circ} \mathrm{C}$ with a final extension for $5 \mathrm{~min}$ at $72^{\circ} \mathrm{C}$. A volume of $8 \mu \mathrm{l}$ of loading buffer (98 per cent formamide, $10 \mathrm{mM}$ EDTA, 0.005 per cent each of xylene cyanol and bromophenol blue as tracking dyes) was added to each of the amplified product and denatured at $94^{\circ} \mathrm{C}$ for $5 \mathrm{~min}$, snap cooled using ice and separated on 5 per cent denaturing polyacrylamide gels (PAGE) 
containing $7 \mathrm{M}$ urea at a constant current of $100 \mathrm{~W}$. Multiplex loading of amplified products was followed based on the amplified product size range. Three sets of amplified products from the parents and $\mathrm{F}_{1} \mathrm{~s}$ were loaded at an interval of $15-30 \mathrm{~min}$ when the amplified products were distinctly different for their size ranges. The patterns of amplified products across the samples were resolved by silver staining (Panaud et al. 1996).

\section{Results and Discussion}

A total of 75 SSR primer pairs surveyed on the parents CO2 and MNga-1 to identify polymorphic markers, 5 primers did not amplify any product. Among the remaining 70 primer pairs which gave amplification, 57 produced polymorphic bands between parents. The level of polymorphism was found to be 81 per cent and it showed high heterozygous nature of the parents. There were ten different types of banding patterns observed in $\mathrm{F}_{1}$ progenies. The $57 \mathrm{SSR}$ primer pairs producing polymorphic markers were used across 153 progenies. Out of the 57 SSR primers, SSRY32, SSRY36, SSRY83, SSRY339, NS149 and NS890 produced single band, which was polymorphic between parents (Table 1). The two alleles of the six SSR primers were amplified in all true hybrid progenies. Based on the above six primers, 12 progenies out of 153 population were identified as self-pollinated seeds of $\mathrm{CO} 2$ female parent. This is because in the 12 progenies amplified, there were only one allele of the female parent and remaining 141 progenies had both

Table 1. List of SSR primers useful for identification of true hybrid progeny in $\mathrm{CO} 2 \times \mathrm{MNga}-1$.

\begin{tabular}{lllc}
\hline Locus & Forward primer $\left(5^{\prime}-3^{\prime}\right)$ & Reverse primer $\left(5^{\prime}-3^{\prime}\right)$ & Product size (bp) \\
\hline SSRY32 & caaattgcaacaatagagaaca & tccacaaagtcgtccattaca & 298 \\
SSRY36 & caactgtttcaaccaacagaca & attctcgtgaactgcttggc & 134 \\
SSRY83 & tggctagatggtgattattgctt & tgcttactctttgattccacg & 239 \\
SSRY339 & cgcaccaacctcatttatcc & ggcttcacagccgtaaaagt & 213 \\
NS 149 & tcttgctcaagggctcaaat & tttgattccacgaaatctagagaa & 299 \\
NS 890 & taaattgggggttcttgctc & tgcttactctttgattccacg & 324 \\
\hline
\end{tabular}

alleles of the parents (Fig. 1) and the progenies viz. 12, 20, 69, 82, 96, 119, 131, 133, 147, $149,150,151$ produced female parent's (CO2) specific banding pattern in their individuals. The result was again confirmed by the primer SSRY43, where same 12 progenies showed the similar segregation pattern (Fig. 2). After removing the 12 selfed progenies of $\mathrm{CO}_{2}$, the primer SSR399 amplified both alleles (double bands) in all the remaining $141 \mathrm{~F}_{1}$ progenies (Fig. 3) of $\mathrm{CO} 2 \times$ MNga-1. This kind of seed contamination happens, may be due to collection of the same parents' male flowers unknowingly for pollination or collection of seed from non-hybridized fruits of female parent $(\mathrm{CO} 2)$ and seed contamination from other seed lot by human error. The SSR markers identified for true hybrids development in $\mathrm{CO} 2 \times$ MNga-1 population were specific to this cross combination, for new crosses similar kind of homologous markers need to be identified. Similar findings were reported for identifying true hybrids in rice (Ye-yun et al. 2005, Yashitola et al. 2002, Hashemi et al. 2009), cotton (Wu et al. 2001, Asif et al. 2009, Dongre et al. 2011), peanut (Gomez et al. 2008), sugarcane (Manigbas and Villegas 2004, Zhang et al. 2009), sunflower (Iqbal et al. 2010), oilpalm (Thawaro and Te-chato 2009) and cabbage (Liu et al. 2007). In all the above studies SSR markers were used for germplasm identification, cultivar fingerprinting, true hybrid identification, genetic purity testing, parentage confirmation of hybrids, and identify heterotic pattern in hybrids. 


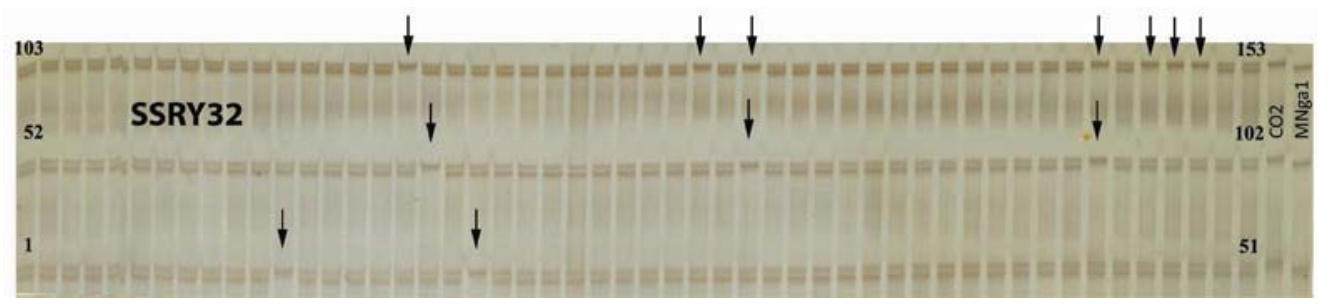

Fig. 1. The marker segregation pattern of SSRY32 in CO2, MNga-1 parents and its $153 \mathrm{~F}_{1}$ progenies. Arrows indicate female parent (CO2) - specific marker $(12,20,69,82,96,119,131,133,147,149$, $150,151)$ and others are true hydrids.

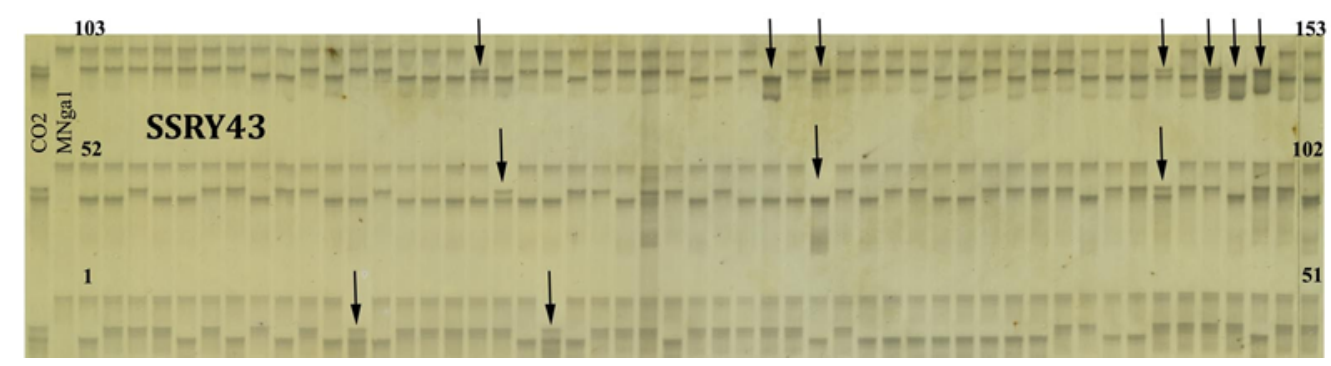

Fig. 2. The marker segregation pattern of SSRY 43 in CO2, MNga- 1 parents and its $153 \mathrm{~F}_{1}$ progenies. Arrows indicate female parent (CO2) - specific marker $(12,20,69,82,96,119,131,133,147$, $149,150,151)$ and others are true hydrids.

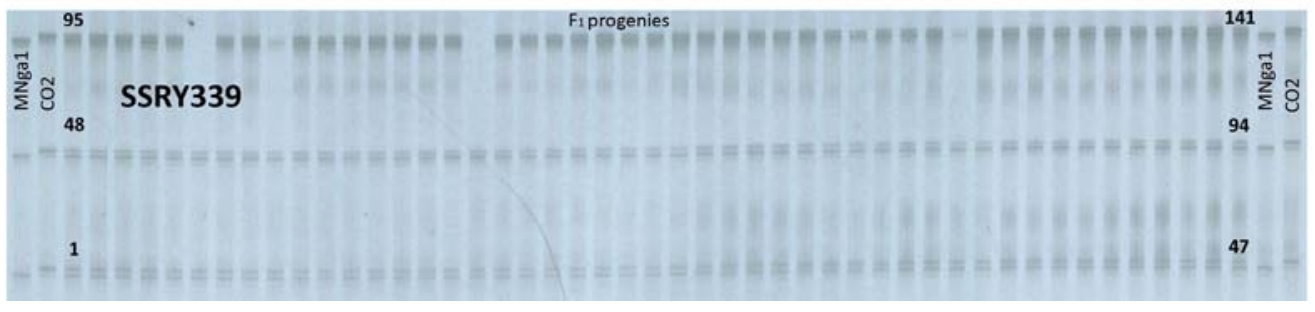

Fig. 3. The marker segregation pattern of SSRY339 in CO2, MNga-1 parents and its $141\left(\mathrm{~F}_{1}\right)$ progenies.

The SSR marker is currently the preferred molecular marker for purity identification in many crops due to its high efficiency and simplicity. The SSR markers, which are producing single allele (homozygous locus) in parents, were very much useful for identification of true hybrids in the early stage of growth. This result in accurate molecular marker genotyping of the progenies for linkage map construction and identifying markers associated with trait of interest more precisely from $F_{1}$ progenies in cassava.

\section{References}

Alves AAC 2002. Cassava botany and physiology. In: Cassava: Biology, production and utilization. (Hillocks RJ, Thresh JM and Bellotti AC Eds.) pp. 67-89. CAB International, UK.

Asif M, Rahman MU, Mirza JI and Zafar, Y 2009. Parentage confirmation of cotton hybrids using molecular markers. Pak. J. Bot. 41: 695-701.

Bianco CL, Fernandez JA, Migliaro D, Crino P and Egea-Gilabert C 2011. Identification of $F_{1}$ hybrids of artichoke by ISSR markers and morphological analysis. Mol. Breeding 27:157-170. 
Crockett PA, Bhalla PL, Lee CK and Singh, MB 2000. RAPD analysis of seed purity in a commercial hybrid cabbage (Brassica oleracea var. capitata) cultivar. Genome 43:317-321.

Dellaporta SL, Wood J and Hicks JR 1983. A plant DNA minipreparation : Version II. Plant Mol. Biol. Rep. 1: 19-21.

Dongre A and Parkhi V 2005. Identification of cotton hybrid through the combination of PCR based RAPD, ISSR and microsatellite markers. J. Plant Biochem. Biotechnol. 14:53-55.

Dongre AB, Raut MP, Bhandarkar MR and Meshram KJ 2011. Identification and genetic purity testing of cotton $F_{1}$ hybrid using molecular markers. Indian J. Biotech. 10: 301-306.

Gomez SM, Denwar NN, Ramasubramanian T, Simpson CE, Burow G, Burke JJ, Puppala N and Burow MD 2008. Identification of peanut hybrids using microsatellite markers and horizontal polyacrylamide gel electrophoresis. Peanut Science 35: 123-129.

Hashemi SH, Maibody SAMM, Nematzadeh GA and Arzani A 2009. Identification of rice hybrids using microsatellite and RAPD markers. African J. Biotechnology 8: 2094-2101.

Iqbal A, Sadaqat HA, Khan AS and Amjad, M 2010. Identification of sunflower (Helianthus annuus, Asteraceae) hybrids using simple-sequence repeat markers. Genet. Mol. Res. 10: 102-106.

Ju-Fen L, Guo-Bin M and Ling X 2008. SSR markers for identification of purity of melon hybrids. Chinese J. Agric. Biotech. 5: 223-229.

Liu LW, Hou XL, Gong YQ, Zhang YM, Wang KR and Zheng JF 2004. Application of molecular markers in variety identification and purity testing in vegetable crops. Mol. Plant Breed. 2: 563-568.

Liu L, Liu G, Gong Y, Dai W, Wang Y, Yu F and Ren Y 2007. Evaluation of genetic purity of $F_{1}$ hybrid seeds in cabbage with RAPD, ISSR, SRAP and SSR markers. Hort. Sci. 42: 724-727.

Manigbas N and Villegas L 2004. Microsatellite markers in hybridity tests to identify true hybrids of sugarcane. Philippine J. Crop Science 29: 23-32.

Mba REC, Stephenson P, Edwards K, Melzer S, Nkumbira J, Gullberg U, Apel K, Gale M, Tohme T and Fregene M 2001. Simple sequence repeat (SSR) markers survey of the cassava genome: towards a SSRbased molecular genetic map of cassava. Theor. Appl. Genet. 102: 21-31.

Moyib OK, Odunola OA and Dixon AGO 2007. SSR markers reveal genetic variation between improved cassava cultivars and landraces within a collection of Nigerian cassava germplasm. African J. Biotech. 6: $2666-2674$.

Nandakumar N, Singh AK, Sharma RK, Mohapatra T, Prabhu KV and Zaman FU 2004. Molecular fingerprinting of hybrids and assessment of genetic purity of hybrid seeds in rice using microsatellite markers. Euphytica 136: 257-264.

Panaud O, Chen X and McCouch SR 1996. Development of microsatellite markers and characterization of simple sequence length polymorphism (SSLP) in rice (Oryza sativa). Mol. Gen. Genet. 252: 597-607.

Thawaro S and Te-chato S 2009. Application of molecular markers in the hybrid verification and assessment of somaclonal variation from oil palm propagated in vitro. Science Asia 35: 142-149.

Wu YT, Zhang TZ, Guo WZ and Yin JM 2001. Detecting polymorphism among upland cotton (Gossypium hirsutum L.) cultivars and their roles in seed purity of hybrids with SSR markers. Cotton Science 13: 131-133.

Wu M, Jia X, Tian L and Lv B 2010. Rapid and reliable purity identification of $\mathrm{F}_{1}$ hybrids of maize (Zea may L.) using SSR markers. Maize Genomics and Genetics 1: 1-4.

Yashitola J, Thirumurugan T, Sundaram RM, Naseerullah MK, Ramesha MS, Sarma NP and Sonti RV 2002. Assessment of purity of rice hybrids using microsatellite and STS markers. Crop Sci. 42: 1369-1373.

Ye-yun X, Zhan Z, Yi-ping X and Long-ping Y 2005. Identification and purity test of super hybrid rice with SSR molecular markers. Rice Science 12: 7-12.

Zhang HY, He LL, Zhong HQ, Li FS, He SC and Yang QH 2009. Identification of intergeneric hybrids between Saccharum spp. and Erianthus fulvus with ITSs. African J. Biotechnology 8: 1841-1845. 